\title{
O CORPO NAS INTERVENÇÕES PARA TRANSFORMAÇÕES DE GÊNERO ${ }^{i}$
}

\author{
Vanessa do Nascimento Fonseca ${ }^{\text {ii }}$
}

\begin{abstract}
Resumo: Este artigo analisa intervenções que foram realizadas com grupos de jovens por meio de projetos sociais em comunidades e em escolas, que visavam à promoção da equidade de gênero. Tais ações educativas partiam de currículos elaborados por uma ONG para apoiar transformações de normas de gênero que interferem na equidade entre homens e mulheres, incluindo práticas de cuidado com a saúde sexual e reprodutiva, prevenção ao HIV/Aids e diferentes formas de violência. Ao longo dos processos com os grupos, o corpo afetado surgiu como elemento fundamental das transformações subjetivas. $\mathrm{O}$ acompanhamento dos processos a partir de preceitos da etnografia, cartografia e pesquisa-intervenção pôs em análise outro olhar sobre o corpo, afinado ao debate feminista crítico dos dualismos mente/corpo.
\end{abstract}

Palavras-chave: Gênero; Subjetividade; Corpo.

\begin{abstract}
Este artículo analizalas intervenciones que se realizaron con grupos de jóvenes a través de proyectos sociales en comunidades y escuelas, que tenían como objetivo promover la equidad de género. Dichas acciones educativas se basaron en planes de estúdio desarrollados por una ONG para apoyar las transformaciones em las normas de género que interfieren em laequidad entre hombres y mujeres, incluídas las prácticas de atención de la salud sexual y reproductiva, la prevención del VIH / SIDA y diferentes formas de violencia. A lo largo de los procesos com los grupos, el cuerpo afectado emergió como un elemento fundamental de las transformaciones subjetivas. El seguimiento de procesos basado em los preceptos de la etnografía, la cartografía y la investigación-intervenciónpuso en perspectiva o travisión del cuerpo, em sintonia com el debate feminista crítico de los dualismos cuerpo / mente.
\end{abstract}

Palabras clave: Género, Subjetividad, Cuerpo.

\section{As tramas que tecem as reflexões desse artigo}

Este artigo analisa intervenções que foram realizadas com jovens, homens e mulheres, por meio de projetos sociais em comunidades e em escolas, que visavam à promoção da equidade de gênero. Tais ações educativas partiam de currículos elaborados por uma ONG para apoiar transformações de normas de gênero que interferem na equidade entre homens e mulheres, incluindo práticas de cuidado com a saúde sexual e reprodutiva, prevenção ao HIV/Aids e diferentes formas de violência. O debate de exemplos considerados positivos de comportamento era avaliado como basilar na promoção de mudanças das normas de gênero que geram iniqüidades entre homens e mulheres. 
Os currículos, compostos por exercícios de grupos, estratégias de mobilização comunitária e elaboração de campanhas sociais, eram testados e avaliados em sua capacidade de produzir mudanças em atitudes e comportamentos por meio de escalas likert ${ }^{\mathrm{iii}}$ e grupos focais. Ressalta-se aqui que o debate sobre as transformações de gênero costumava estar restrito a atitudes e comportamentos machistas, cuja mudança era efetivamente mensurada. As intervenções tinham como objetivo apresentar e ensaiar modelos considerados positivos de resolução dos conflitos, sobretudo nas relações amorosas entre casais cisheterossexuais, que gerariam impacto na saúde e na redução de violência de gênero. Os exercícios de grupo ofereciam cenários para que os e as jovens representassem e discutissem práticas de cuidado e de relações mais equânimes ${ }^{\text {iv }}$. Campanhas comunitárias e sociais, baseadas em estratégias de marketing social ${ }^{v}$, ofertavam exemplos não machistas, não violentos e de cuidado com sua própria saúde e do parceiro ou parceira.

Não são raros, sobretudo com homens, estudos que avaliem a alteração de comportamentos machistas para comportamentos que favoreçam relações mais justas com as parceiras e o cuidado com a saúde do casal. Muitos pesquisadores demonstram os impactos das intervenções com homens e meninos na transformação das masculinidades, criando instrumentos de verificação, indicadores e teorias de mudança que ajudaram a divulgar a importância da criação de abordagens para o envolvimento dos homens nas ações para a equidade de gênero. Boa parte de tais instrumentos de verificação se concentra na avaliação de mudanças individuais de atitudes e comportamentos machistas, favorecendo a criação de abordagens que priorizam a reprodução de modelos esperados de como homens e mulheres devem se comportar em relações equânimes.

Raewyn Connell (2016) nos apresenta inúmeros exemplos documentados da capacidade de homens e meninos sustentarem a igualdade. A autora afirma que uma série de pesquisas em educação e psicologia na Austrália atesta que é possível ensinar meninos a terem flexibilidade face aos estereótipos de gênero. A produção de ferramentas e de evidências sobre a eficácia na transformação de atitudes machistas, no entanto, não é suficiente para a compreensão das razões que levariam os homens a se engajar em projetos para a equidade de gênero e transformar seus comportamentos (CONNELL, 2016). É necessário aprofundamento e outros instrumentos para uma compreensão mais ampliada das motivações para a transformação de normas de gênero.

Em sintonia com essa noção, além dos modos de avaliação citados, o trabalho com os grupos era realizado a partir dos princípios da pesquisa-intervenção, da etnografia e da abordagem cartográfica, em que os processos eram mapeados, analisados a cada encontro e serviam como instrumento da própria intervenção.Todos os acontecimentos do campo eram Revista Interinstitucional Artes de Educar. Rio de Janeiro, V. 7, N. 1 - pág. 333-355 janeiroabril de 2021: "Pedagogias Vitais: Corpo, Desejo e Educação" DOI: 10.12957/riae.2021.54793 


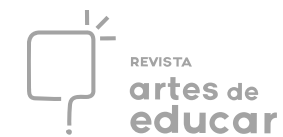

registrados regularmente em diários, com base no preceito etnográfico de que as atitudes e comportamentos humanos só podem ser pensados no contexto (VICTORA, KANAUTH e HASSEN, 2000). As reações, os conflitos, os afetos, os cenários, as paisagens, os movimentos, os relatos, tudo o que era ouvido e vivido era descrito para ser analisado posteriormente e dar forma a novos mapeamentos dos processos em campo.

A influência do método cartográfico ${ }^{\mathrm{vi}}$ reforçava a noção de que não se tratava apenas do relato de opiniões ou da interpretação dos fatos, mas do acompanhamento dos acontecimentos em sua processualidade, em seu movimento. Desse modo, os registros abriam espaço para mergulhos e variações de perspectivas das experiências vividas e compartilhadas com o grupo, sem encobrir os "tensionamentos de um movimento que se inscreve em uma realidade complexa e multireferencializada" (AGUIAR e ROCHA, 2007, p. 651). Importa ainda mencionar, como o fazem Simone Paulon e Roberta Romagnoli (2010), que a complexidade referida aqui não tem sentido de algo de difícil compreensão, mas significa que os processos não se reduzem a unidades simplistas de explicação. Para as autoras, aproximarse de uma realidade complexa implica romper com uma abordagem não dualista e suas dissociações de natureza/cultura e objetivo/ subjetivo.

Desse modo, novas intervenções eram planejadas com os grupos trabalhados a partir dos diários de campo, nos encontros alimentados por tensões e outros afetos que atravessavam os corpos de cada um, a partir da confluência entre o que era proposto e suas experiências. $\mathrm{O}$ currículo de atividades educativas foi totalmente adaptado e subvertido, reforçando a necessidade da narrativa cartográfica dos encontros, de modo a escapar de falsas relações de causa e efeito estabelecidas pelos métodos de avaliação comportamentais aqui mencionados. Ou seja, se existe variação de pensamento no grupo antes e depois da intervenção, isto se deve a série de acontecimentos e outras ferramentas que compuseram os dispositivos iniciais. As experiências são diversas entre os grupos. É preciso acompanhá-las. Não é possível creditar as mudanças apenas ao currículo, mas existe uma série de eventos em campo capazes de provocar deslocamentos diversos.

As possibilidades apresentadas pelas ferramentas e os princípios ético-políticos de pesquisa adotados trouxeram para a cena o corpo, não apenas no discurso, mas encarnado nos processos de transformação de gênero. Tal transformação, mais do que sustentada na produção de melhores indicadores de saúde sexual e reprodutiva e violência, passou a ser vista como resgate de nossas possibilidades criativas de existência. $\mathrm{O}$ rompimento com os processos de captura subjetiva e de normalização dos sujeitos, próprio do gênero no sistema colonialcisheteropatriarcal-capitalístico $^{\text {vii }}$, foi percebido como elemento fundamental de uma Revista Interinstitucional Artes de Educar. Rio de Janeiro, V. 7, N. 1 - pág. 333-355 janeiroabril de 2021: "Pedagogias Vitais: Corpo, Desejo e Educação" DOI: 10.12957/riae.2021.54793 
transformação que não tem um fim pré-estabelecido, mas é processual, característica da vida em seus encontros.

Para melhor compreensão dos deslocamentos educativos produzidos, interessa assinalar que o debate sobre gênero, quando incluído nos processos de formação de jovens e adolescentes, costumava ter como finalidade a saúde sexual e reprodutiva, incluindo prevenção do HIV/Aids, DSTs e violência sexual. Outra preocupação frequente era evitar gravidezes nessa faixa etária. Os Parâmetros Curriculares Nacionais (PCN) de 1996 serviram, durante muitos anos, como instrumento para a defesa de ações que envolvessem educação sobre gênero e sexualidade. Embora no documento da década de 1990 estivesse explícito que organismo e corpo são diferentes, de modo que a inclusão do corpo nos processos de formação não se resume a descrição de funções fisiológicas, o corpo é inserido nesse debate conceitualmente, seja para fazer uma distinção com a ideia de gênero, seja para justificar cuidados diferenciados com o corpo masculino e feminino, ou para informar sobre o aparato sexual e reprodutivo. O que se observava na prática das intervenções voltadas para a equidade de gênero com jovens é que trabalhar o corpo nos programas relacionados ao gênero dizia respeito a distinguir gênero do aparato sexual e produzir conhecimento sobre tal aparato, para que mulheres e homens façam escolhas relacionadas ao cuidado de sua saúde. O conhecimento do corpo, reduzido às funções biológicas da reprodução, tem sido prerrogativa principal quando pensamos a equidade de gênero.

No entanto, mais do que estar atento ao funcionamento biológico do corpo e discutir valores e normas que interferem na vivência singular do prazer e expressão dos desejos, o corpo é potente instrumento de produção e transformação de subjetividade. Ao desenvolver oficinas de diferentes temáticas para a promoção a equidade de gênero, o corpo era acionado de diferentes maneiras. Ao acompanhar os processos grupais, as ideias produzidas pelos participantes, que faziam sentido, eram visivelmente corporificadas, eram sentidas e percebidas no corpo. Era visível no corpo uma mudança de postura, ou mesmo a desconstrução/ desincorporação de normatizações de gênero, quando algo lhes afetava. Durante os encontros em grupo, algo atravessava seus corpos de modo a abrir espaço para a produção de desejo; suas histórias, posicionamentos e as ideias que tinham de si mesmos/as eram ressignificadas. Essa observação nos levou a experimentar atividades que visavam afetar os corpos, ou seja, atravessá-los de sentimentos e sensações capazes de produzir desejos e deslocá-lo para novos territórios subjetivos, tal como Sueli Rolnik tem trabalhado em sua obra. Pensar transformações nas normas de gênero passou a ir além da reparação de injustiças e do equilíbrio de oportunidades entre homens e mulheres. Enfrentar as opressões de gênero requeria a expansão 
das possibilidades criativas de existência, de desejos, tal como fala Sueli Rolnik (2018). Para tal, o corpo como local de produção de subjetividade não poderia estar de fora.

Diante do cenário apresentado, a redação do presente artigo traz análises da presença do corpo nas intervenções para a transformação das normas de gênero em intervenções com grupos de jovens. Pensar o corpo a partir de uma perspectiva não binária de sua relação com a subjetividade tem se mostrado fundamental para a desessencialização do gênero, etapa necessária a abertura para a criação de outras formas de ser.

Por fim, cabe informar que as análises aqui realizadas se concentram, principalmente, nos registros de um trabalho realizado com trinta jovens de projetos educativos de três comunidades em 2005 e 2006 e, posteriormente, em 2010, em um projeto em que o corpo ganhou centralidade nas intervenções, realizado em uma escola da Região Metropolitana do Rio de Janeiro. Nesse período, embora houvesse oposição à pauta nas escolas, as reações provocadas por projetos como "Escola sem partido" ou o debate em torno da chamada "ideologia de gênero" não tinham a consistência que alcançaram nos anos seguintes até a publicação deste texto. Os registros e a memória acionada por sua leitura são, aqui, reexplorados a partir de novas perspectivas que se afirmaram nos últimos anos no Brasil, sobretudo o feminismo decolonial e interseccional.

\section{Efeitos da construção do gênero sobre o corpo}

Apesar dos desafios de trazer o corpo para além das informações sobre o aparato reprodutivo e de sua oposição ao gênero nos processos educativos com jovens, o corpo na teoria feminista contemporânea ganhou centralidade como lócus de produção de subjetividade e fonte de resistência, conforme argumenta Margareth McLaren (2016). De acordo com a autora, o dualismo mente/corpo, em sua excessiva valorização da razão e descorporificação da subjetividade, tem sido alvo de diversas críticas feministas. A observação da associação das mulheres à natureza e às emoções, enquanto os homens estiveram relacionados à cultura e à razão, motivou análises críticas desse antagonismo.

A oposição entre natureza e cultura foi baseada em processo hierárquico que desvalorizou os seres considerados mais próximos da natureza (mulheres, não brancos, não europeus, não adultos) e legitimou o poder dos homens, cuja racionalidade foi atributo considerado necessário por excelência à participação política e ao exercício do poder. O corpo 
costuma ser percebido apenas por sua relação com essa ideia de natureza separada de todos os processos de produção e criação humanos.

A busca por neutralidade, ou como se refere Donna Haraway (1995), objetividade científica descorporificada, favoreceu o domínio da natureza, das mulheres e dos povos ditos não civilizados. Dessa maneira, fomos nomeados pela utilidade, semelhança e diferença binária (0-1), por meio de cisões ainda mais aprofundadas entre natureza e cultura, feminino e masculino, racional e irracional (AGUIAR, 2012). Os humanos foram divididos entre os que supostamente se aproximavam da ideia de natureza (mulheres, quilombolas, indígenas) e os que eram mais eficientes no exercício político e científico (homens, brancos, adultos, europeus). A diversidade das formas de viver humanas foi submetida a modelos de expressão desejáveis e aceitáveis (AGUIAR, 2012). Os corpos foram capturados por sistemas que os categorizaram, segmentaram em diferentes partes, definiram funções, além de o excluírem dos próprios processos de subjetivação criativas. Não apenas rotulado por gênero, raça e faixa etária, o corpo teve suas possibilidades de produção de subjetividade capturadas por diferentes instituições do sistema social e econômico que nos governa.

O corpo nas sociedades coloniais-cisheteropatriarcais-capitalísticas, reduzido a sua materialidade, é visto como julgamento final para o que somos ou o que podemos nos tornar (WEEKS, 2000). Esperamos que a materialidade do corpo, aquela que tem interessado aos estudos biomédicos, dite uma identidade, sem ambiguidades ou inconstâncias, incompatível com um mundo de incertezas, em constantes fluxos (WEEKS, 2000). Descrevemos o que somos (gênero, raça, faixa etária) a partir das marcas corporais tidas como binárias. As dissidências subjetivas, que escaparam ao que foi estabelecido com base em determinadas marcas corporais, foram subtraídas pelo designo de outro, de desviante, anormalidade. Coubelhes a tutela e a confinação em instituições próprias para sua separação da sociedade ou para a tentativa de adequação aos padrões tidos como aceitáveis.

As ciências, criando normas de padronização e valor, atravessam, marcam o corpo, rotulam e o tornam efeito e agente de difusão de saber (SOUZA, ARNT E RABUSKE, 2007). A medicina, a psiquiatria, a pedagogia e também as ciências sociais produziram um sistema de conhecimentos que se sobrepôs a percepção que os sujeitos têm de si e a sua capacidade de se inventar. A legitimação desse processo de produção de conhecimento e de práticas sobre os corpos tem servido não apenas para definir as relações entre homens e mulheres, mas favoreceu propósitos colonizadores e capitalistas.

As críticas feministas à colonialidade da produção de saber e das práticas, inclusive das lutas emancipatórias, ajudou a superar a concepção de gênero como uma categoria descritiva Revista Interinstitucional Artes de Educar. Rio de Janeiro, V. 7, N. 1 - pág. 333-355 janeiroabril de 2021: "Pedagogias Vitais: Corpo, Desejo e Educação" DOI: 10.12957/ riae.2021.54793 
dos comportamentos e atitudes. Para além do estabelecimento de regras que regem comportamentos, o patriarcado, sistema ocidental que rege as relações entre homens e mulheres, age por uma reiterada ação de drenagem e expropriação das possibilidades criativas de existência das mulheres, amalgamada com o capitalismo, a colonialidade (GUTIÈRREZ AGUILAR, 2018) e a cisheterossexualidade ${ }^{\text {viii }}$ compulsória. Tais expropriações são sustentadas por todos os regimes corporais e artifícios de produção de saber que legitimam a partir de onde devemos posicionar para definir os rumos do mundo.

Diferente do machismo, que se refere a condutas sexistas, o patriarcado é o sistema de todas as opressões e violências que vivem a humanidade e a natureza, construído historicamente sobre o corpo das mulheres (PAREDES, 2016). Nesse sentido, um trabalho verdadeiramente transformador e emancipatório de gênero precisa fazer cindir o sistema que age na anulação das capacidades políticas e criativas de vida e coletividade dos grupos. O corpo está incluído nesse processo de abertura para outros modos de criação de vida, tal como o trabalho com grupos de jovens nos mostrou. Assim, o que proponho é, em vez de restringirmos nosso olhar para os efeitos do gênero e os comportamentos que os instauram, reforçando posições de vítima e algoz, que olhemos para as forças que capturam as possibilidades criativas de vida, bem como saídas para as relações de sujeição, a partir de outra presença do corpo nos processos de formação de jovens para o enfrentamento das opressões de gênero.

A crítica ao gênero como uma categoria de descrição cultural de um corpo biológico não tem sido de simples aplicação, no entanto. O conceito de gênero percebido como a construção social do sexo (corpo biológico) tem definido ainda boa parte da produção de conhecimento e de políticas que envolvem o enfrentamento dos efeitos do patriarcado. Esse caminho produz transformações limitadas, em que o olhar sobre gênero reduzido a uma diferença sexual (porque ancorado no sexo), segundo Teresa de Lauretis (2019, p. 121), cria espaços "gendrados", "nos quais a própria diferença sexual pudesse ser afirmada, tratada, analisada, especificada, verificada". Assim, uma das limitações apontadas por autoras feministas (NICHOLSON, 2000; LAURETIS, 2019) é a universalização da dicotomia sexual e das mulheres. Desse modo, se não é mais o biológico que determina a semelhança entre esse grupo, o social, ancorado na construção dos sujeitos a partir do sexo, passa a definir a homogeneização feminina, tal como explica Butler (2008).

Linda Nicholson (2000) elabora a noção de fundacionalismo biológico para compreender os obstáculos à compreensão das multiplicidades entre mulheres. Diferente do determinismo biológico em que a anatomia sexual é o destino dos seres humanos, concepções com base no fundacionalismo biológico permitiriam a incorporação de elementos do Revista Interinstitucional Artes de Educar. Rio de Janeiro, V. 7, N. 1 - pág. 333-355 janeiroabril de 2021: "Pedagogias Vitais: Corpo, Desejo e Educação" DOI: 10.12957/riae.2021.54793 
construcionismo social. No entanto, embora permita a entrada de aspectos além do biológico na construção do comportamento e do caráter - o que explicaria maior diversidade entre as culturas -, tal diversidade se limita a certa quantidade de diferenças entre mulheres. Não há avanço na ultrapassagem da dicotomia homem x mulher, quando se generaliza para outras culturas, binarismos característicos do que convencionamos chamar de ocidente, algo também alertado por Oyèronké Oyewùmí (2004) a respeito da incompreensão dos modos de organização social dos povos africanos por parte de feministas e pesquisadores sociais.

De acordo com Linda Nicholson (2000), pensar as diferenças entre as mulheres por meio do fundacionalismo biológico depende da coexistência (e não interseção) da raça e da classe. Ou seja, gênero será responsável por tudo que há em comum entre as mulheres, enquanto a diversidade feminina será baseada nos demais marcadores sociais. Essa concepção não dá conta da noção de interseccionalidade que tem sido trabalhada por feministas negras como Kimberly Crenshaw (2002) e Audre Lorde (2019), para as quais a interseccionalidade não é uma soma de fatores de opressão, mas a articulação entre diferentes categorias sociais introduz a desigualdade de outro modo. Assim, mulheres negras seriam oprimidas pelo racismo/ sexismo de modo distinto dos homens negros e das mulheres brancas. A experiência de ter um corpo marcado pela raça e pelo sexo produz um tipo de opressão diferente, que articula esses dois fatores.

De modo similar, Teresa de Lauretis (2019) afirma que o conceito de gênero restrito à diferença sexual "tende a reacomodar ou recuperar o potencial epistemológico radical do pensamento feminista sem sair dos limites da casa patriarcal” (p. 122). Por potencial epistemológico radical, a autora explica que se refere às possibilidades abertas pelo feminismo, sobretudo negro, da década de 1980, em que as relações de subjetividade com a sociabilidade são analisadas sob outras bases, nas quais o sujeito, engendrado nas relações de gênero, raça e classe é "múltiplo em vez de único, e contraditório em vez de simplesmente dividido" (LAURETIS, 2019, p. 123). São as capturas coloniais-cisheteropatriarcais-capitalísticas de produção de sentido que constituíram as noções de sexo e de gênero como distintas, mas cristalizadas, seja biologicamente ou culturalmente, de modo a turvar nossa percepção das contradições, singularidades e constante processo de diferenciação que nos constitui.

De fato, considerar algo como construído culturalmente abre mais espaço para transformações. Mesmo que reconheçamos o status evolutivo da natureza, e as sociedades capitalistas visem desenvolver técnicas de domínio e modificação de bens naturais, a natureza tem sido utilizada para afirmar uma essência que deve ser preservada nas questões que dizem respeito à subjetividade. Por outro lado, não raro, em intervenções com grupos de diferentes Revista Interinstitucional Artes de Educar. Rio de Janeiro, V. 7, N. 1 - pág. 333-355 janeiroabril de 2021: "Pedagogias Vitais: Corpo, Desejo e Educação" DOI: 10.12957/riae.2021.54793 
países, a cultura foi invocada como algo a ser mantido. Nas formações com homens para a equidade de gênero em diferentes países, esses costumam justificar a necessidade de valorização e manutenção da cultura como impedimento a transformação das masculinidades. Como veremos adiante, ignorar que as marcas das atribuições culturais e sociais são de difícil circunscrição e precisam ser frequentemente reforçadas, dificulta-nos a visão do que clama por escapar, da indefinição clara das bordas das categorias sociais. Isto é, invisibilizamos a diferença e nosso constante processo de construção de nós mesmos, bem como todas as conexões que não respeitam os limites corporais e sociais que são estabelecidos. Aqui, na contramão dessa ordem, defendemos o uso de outra política de compreensão dos processos de produção de subjetividade, em que o corpo é constituinte desse curso, não em oposição, nem como base de inscrição do sujeito, mas como componente ativo desses processos por sua capacidade de afetação e consciência.

A distinção entre natureza-biologia-corpo/ cultura-subjetividade limita a dessencialização radical do gênero. Ademais, não é possível relativizar a cultura ou as práticas sociais, baseando-nos em uma natureza universal (LATOUR, 2013). Enquanto não compreendermos que a natureza não é a base comum e unificadora dos povos - sobre a qual a cultura varia -, continuaremos a operar pela separação entre o que é humano (com seus atributos específicos de racionalidade e consciência) e não-humano (associado à natureza). Como mencionado nesta seção, é a partir dessa separação, que temos criado hierarquias entre os que estão mais próximos desse conceito de humanidade (homens, cisheterossexuais, brancos, europeus, adultos) - quem é imediatamente enxergado na criação de políticas e estabelecimento de direitos - e os não-humanos (mulheres, negras, indígenas, crianças, idosos, trans, homossexuais) - os que precisam levantar a voz e marcar uma diferença, para que suas demandas sejam incluídas. Com a separação entre natureza e cultura, as genitálias seguem sendo a base para a compreensão das diferenças nas relações interculturais de gênero, além de serem o eixo (limitado) sob o qual são acionadas as reivindicações emancipatórias.

Desnaturalizar a noção de corpo é, portanto, fundamental para que possamos ampliar o olhar para as possibilidades de diferenciação entre pessoas não apenas de culturas diferentes, mas também de uma mesma cultura. É preciso entender que "existem formas culturalmente variadas de se entender o corpo" (NICHOLSON, 2000, p.14). Compreender isso, bem como a relação do corpo com os processos de produção de subjetividade, envolve questionar o olhar colonizador-cisheteropatriarcal-capitalísticos obre o corpo, que tem servido como base para se pensar o gênero e as intervenções que visam o enfrentamento dos efeitos das relações entre sujeitos gendrados nas sociedades patriarcais. 


\section{Para além da separação corpo-sexo/gênero}

A obra foucaultiana a respeito do corpo tem sido útil às análises feministas que visam romper com a limitação dos sujeitos em categorias sociais enrijecidas, normalizadas (BUTLER, 2008; MCLAREN, 2016; LAURETIS, 2019). Segundo McLaren (2019), como muitas feministas, Foucault rejeita a redução cartesiana da subjetividade à consciência, que é pano de fundo para o dualismo mente/ corpo. Além disso, o autor "politiza o corpo, e suas noções de práticas disciplinares e micropoder são ferramentas úteis para a análise feminista do corpo" (MCLAREN, 2016, p. 109). A preocupação foucaultiana sobre a forma como as normas sociais operam nos corpos é a mesma das feministas sobre como as normas patriarcais afetam os corpos. Outrossim, é que ambos consideram que a subjetividade é corporificada, efeito do poder sobre os corpos. Desse modo, tanto Foucault quanto determinadas correntes do feminismo "rejeitam o dualismo mente/corpo, ambos vêem o corpo como local de luta política, e ambos têm o corpo como central para a subjetividade e a ação” (MCLAREN, 2016, p. 110). Nesse sentido, o corpo não é apenas a tábua de leitura ou de estabelecimento social para comportamentos. É ele mesmo constituído e constituinte dos processos de subjetivação.

Embora Foucault não tenha explicitado, a construção cultural do corpo é sempre de gênero (MCLAREN, 2016). Segundo Lauretis (2019), assim como para Foucault a sexualidade não é uma propriedade dos corpos, gênero também não o é. Com base na ideia do autor, Lauretis afirma que o gênero é efeito de "uma tecnologia política complexa" (FOUCAULT, 1988, p. 121; LAURETIS, 2019, p. 123), em que o discurso é inscrito no corpo por meio de uma série de práticas ou atos que emanam dos diferentes dispositivos institucionais: a família, a religião, o sistema educativo, os meios de comunicação, a medicina ou a legislação, mas também, de fontes menos evidentes, como a linguagem, a arte, a literatura, o cinema e a teoria (LAURETIS, 2019).

Margareth MacLaren (2016) salienta que as normas sociais patriarcais não são simplesmente impostas externamente, mas são internalizadas, constituem os corpos. A maioria das feministas reconhece que "as normas de gênero não são simplesmente regras ou orientações sociais inócuas que nos dizem como agir e nos vestir" (MCLAREN, 2016, p. 129), tal como Julieta Paredes (2016) e Raquel Gutièrrez Aguilar (2018) desenvolvem a partir do conceito de patriarcado, mencionado anteriormente. Gênero funciona como uma ordem compulsória constante que exige coerência entre os genitais e o desejo e estrutura identidades inteligíveis a partir da hierarquia entre masculino e a heterossexualidade (BUTLER, 2014). Gênero não é o mesmo que lei ou uma regra, mas uma norma que funciona como força Revista Interinstitucional Artes de Educar. Rio de Janeiro, V. 7, N. 1 - pág. 333-355 janeiroabril de 2021: "Pedagogias Vitais: Corpo, Desejo e Educação" DOI: 10.12957/riae.2021.54793 


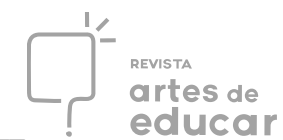

reguladora das leis, de modo explícito ou não (BUTLER, 2008). Sua operação constitutiva e normalizadora dos sujeitos é implícita, difícil de ser reconhecida, atravessa os corpos e é confundida como sendo natural.

A noção de performatividade de Butler nos oferece a dimensão da necessidade da reiteração das práticas que constituem o gênero nos processos de produção subjetiva, bem como uma relação com o corpo que subverte seu lugar de causa para definições do que é ser homem e o que é ser mulher. Nesse sentido uma "identidade é performativamente constituída, pelas próprias 'expressões' tidas como seus resultados" (BUTLER, 2008, p. 48), de modo que "não há identidade de gênero por trás das expressões de gênero" (idem). Sara Salih (2012) afirma que tanto para Butler quanto para Beauvoir, gênero é um processo ou um "devir" que não tem origem, nem fim, de modo que é algo que "fazemos" e não que "somos" de fato. Gênero é algo que se constitui no próprio ato de fazer, não é anterior ou posterior a tal ato. É um fazer constante. O que dá a imagem de estabilidade, de sustância ou de forma natural, é seu processo contínuo de estilização do corpo, por meio de um quadro regulatório rígido (BUTLER, 2008).

Dizer que gênero é performativamente construído não é o mesmo que dizer que é performado, pois não é um papel que é representado. Para que se consolide, é preciso que seja reiterado com freqüência no cotidiano das práticas, das cerimônias, das relações. Somos freqüentemente provocados a nos comportar como homens e mulheres por meio de uma repetição incorporada de gestos, movimentos e estilos (ARÁN e PEIXOTO JÚNIOR, 2007). Esse processo, embora de efeitos de extrema violência, é construído tenua e consistentemente através do tempo, o que nos dá a impressão de que seus resultados conformam nossa essência. Mas é também fonte de resistência aos modos de subjetivação de gênero. Na necessidade de repetição contínua da norma, consiste a inventividade da vida, seu movimento constante de dar forma a si mesma. Algo sempre escapa.

Um aparente paradoxo da perspectiva foucaultiana sobre o corpo também foi abordado por diversas feministas para pensar a sujeição e a resistência ao gênero. Butler (2008) analisa que se o corpo é lugar de inscrição cultural para Foucault, isso significa que uma materialidade anterior é assumida, algo sob o qual se gravar as normas sociais. Ademais, como coloca McLaren (2016), como é possível pensar a resistência sem uma noção de corpo que não esteja reduzida a sua produção social? Em outras palavras, se o corpo se constitui por normas sociais, nada escaparia a tal produção e não seria necessário resistir a ela, de modo que a ação feminista é minada.

A resistência é um elemento, segundo Foucault (2014), da relação estratégica em que consiste o poder; jamais ocupa uma posição de exterioridade às relações de poder, mas são Revista Interinstitucional Artes de Educar. Rio de Janeiro, V. 7, N. 1 - pág. 333-355 janeiroabril de 2021: "Pedagogias Vitais: Corpo, Desejo e Educação" DOI: 10.12957/riae.2021.54793 
componentes desse elo. Se não houvesse resistência, tudo seria apenas uma questão de obediência (FOUCAULT, 2014). Para este autor, resistência é um processo de criação, mais do que negação. Tal processo inclui criar e recriar, além de transformar. Isso "quer dizer que temos sempre a possibilidade de mudar a situação [...] Não podemos nos colocar de fora da situação, e em nenhum lugar estamos livres de toda relação de poder. Mas podemos sempre transformar a situação” (FOUCAULT, 2014, p 256).

Em sua elaboração teórica mais tardia, as práticas corporais foram pensadas por Foucault também como práticas de si, necessárias a subjetividade ética (MCLAREN, 2016, p. 131). Cuidar da vida como uma obra a ser constantemente analisada e esculpida, é o que leva a transformação e a modos outros de se relacionar. Trata-se de um processo constante de apropriação da vida como produtora de diferenciação, o que significa subverter a lógica da matriz do gênero colonial-cisheteropatriarcal-capitalística. O cuidado de si envolve conhecerse, mas não conhecer a própria essência. É conhecer as forças que nos atravessam e se criar nesse processo. Com os grupos, trata-se de fazer um trabalho de sentir a vida impregnada em corpos atravessados por diversas intensidades e que criam suas bordas a partir da composição dessas intensidades. Caminhamos no sentido de fortalecer as conexões da vida com o corpo, não com os genitais, o tom de pele e outros órgãos, mas com seus afetos, fluxos, consistências e pulsos.

$\mathrm{Na}$ prática das transações de gênero, como visto, os sentidos das relações e das subjetividades são forjados em meio a inúmeros aparatos que agem de forma combinada e reiterada para nos afastar da possibilidade inventiva de nossas relações no entre nós. Mas nesse processo, há sempre disparidades e desestabilizações, que nos fazem concluir que as tecnologias de gênero operam de forma precária na produção de sujeitos de enunciação e de ação (LAURETIS, 2019). Tal lógica da produção do gênero gera uma série de contradições e podem levar ao colapso os processos de existência e o corpo, na medida em que o que está posto não representa o que se vive no plano sensível (DONINI, 2010). Uma ordem binária, como a do gênero, não pode dar conta da diversidade de experiências vividas.

Desse modo, considerar que gênero opera nos processos de produção de subjetividade, por meio de um sistema que aparenta estabilidade e coerência entre os sujeitos, não significa que uma verdade ou essência seja de fato produzida em homens e mulheres. É justamente essa noção que estamos enfrentando neste texto. A cristalização ou a naturalização do que se entende como comportamentos ou desejos masculinos e femininos é uma ficção que não serve a todas as pessoas. Na prática das intervenções sobre gênero com jovens, a inconsistência dos sentidos de ser homem e ser mulher é visível. Era a partir da atenção a inconsistência sentida por um Revista Interinstitucional Artes de Educar. Rio de Janeiro, V. 7, N. 1 - pág. 333-355 janeiroabril de 2021: "Pedagogias Vitais: Corpo, Desejo e Educação" DOI: 10.12957/riae.2021.54793 
corpo que era afetado pelas dissonâncias e contradições de gênero presentes nos encontros que os fios das transformações eram tecidos.

\section{Modulações corporais nas intervenções sobre gênero}

A apatia tradicional nos processos de formação é capaz de gerar informação, mas não é apenas a informação, ou a simples consciência de nossa situação, que produz mudanças. Gênero, como uma abordagem crítica em projetos que visam à emancipação social, não é um conceito que deva ser simplesmente memorizado (FONSECA, 2011). Não é possível ser transformador de gênero pela reprodução de modelos aprendidos. Uma discussão, se não nos toca, é apenas capaz de promover a repetição do discurso.

No trabalho com os grupos de jovens eram notáveis dois momentos de mudança. O primeiro acompanhava a repetição de palavras debatidas sobre comportamentos mais saudáveis de gênero, como "um homem não deve bater em uma mulher em nenhuma circunstância", ou "todas as pessoas têm o direito de se relacionar com quem quiser, independente do gênero". Tais ideias respondiam bem às demandas das escalas que mediam atitudes e comportamentos de gênero. No entanto, na prática, dissonâncias eram reveladas por determinadas posturas nas relações de grupo ou mesmo pela diversidade de experiências que não cabem no escasso repertório que conseguimos elencar de atitudes e comportamentos conhecidos de gênero. Por exemplo, embora dissessem respeitar e ser contra piadas contra homossexuais, visivelmente não acolhiam da mesma forma o menino que parecia gay. Uma das poucas atividades que se recusaram a participar, por diferentes desculpas, foi a parada gay. Por outro lado, meninos pobres e negros não eram violentos com suas parceiras. Em alguns casos, eram até subservientes. Desenvolviam doçura extrema para romper com a imagem do homem negro ameaçador, o que, nas ruas, não os livrava das perseguições dos seguranças ou dos desvios de pessoas que temiam assaltos. Esses fatos só puderam ser revelados por um acompanhamento atento e pela abertura ao desenrolar dos processos no grupo. Também não cabiam em outro modo de avaliação em que possíveis respostas eram pré-elaboradas.

O segundo momento se caracterizava pela criação de discursos e de lutas que eram próprias aos/às jovens, e era sucedido pela visível mudança de tônus e postura corporal. Seus posicionamentos passavam por deslocamentos que resultavam da afetação de seus corpos, a partir da reverberação em suas vidas das experiências propostas em grupo. 
A partir de então, interessei-me pela relação entre corpo e resistência ao gênero, não apenas pelo reconhecimento da inadequação entre genitálias e expressões de gênero, mas pela criação de dispositivos capazes de gerar afetos que atravessassem os corpos. Por afeto, refirome às vibrações que perpassam os corpos, abrindo-os a reconfigurações subjetivas. Assim, as formações saíram de um processo de debates sobre a relação entre gênero e o corpo, e possibilidades de mudanças por meio de exemplos e histórias de comportamentos positivos de masculinidades e feminilidades, para a experimentação do gênero no corpo, por meio de dispositivos que afetassem os corpos.

Os dispositivos utilizados nas formações incluíram experimentações e movimentos corporais, dentre os quais menciono técnicas, como o movimento autêntico, aprendidas na Faculdade Escola de Dança Angel Viana ${ }^{\text {ix }}$, que procurei depois de ser desafiada pelas questões do corpo colocadas pelos trabalhos de formação com jovens. A obra de Lygia Clark também inspirou intervenções com os grupos de projetos sociais e, mais particularmente, de uma escola da rede pública, em parceria com as professoras de artes e história. As reflexões de Suely Rolnik, Gilles Deleuze e Félix Guattari conduziram o processo de criação das intervenções propostas.

É mister mencionar que, na escola, a sensibilização e atuação conjunta de professores, coordenadora pedagógica e direção foram fundamentais para a implementação de um plano político pedagógico que trouxe o corpo para a cena de um modo diferente, buscando afetá-lo com a readequação do espaço e experimentações artísticas. Uma sala teve as cadeiras substituídas por almofadas, permitindo-nos fazer diferentes intervenções corporais e instalações interativas que relacionávamos ao tema do gênero.

Mais do que palavras, as intervenções passaram a ser preenchidas com outros modos de organizar e estar no espaço; com outros modos de fazer desdobrar o pensamento, através de linguagens que estão além da fala: objetos, acontecimentos, imagens, cenas, experiências outras capazes de liberar variadas conexões com o que nos cercam. Por meio de movimentos (caminhar, agir como mulher, agir como homem), propúnhamos a observação de seu corpo e dos corpos em volta, embalados por movimentos próprios. Os encontros eram geradores de gestos, intenções, sentimentos, intensidades, aproximações e distanciamentos. Nesta relação, atentávamos para o que havia de singular e também de ressonante dos outros corpos em nós. Indagávamos sobre o que nos levava a mover e como éramos afetadas pelo que estava à volta. Fazíamos relações com questões de gênero.

O movimento autêntico tomava os encontros como objeto de investigação, e ao fazê-lo, refletíamos sobre relações sociais, desejo, autonomia e direitos. Trata-se, portanto, de uma Revista Interinstitucional Artes de Educar. Rio de Janeiro, V. 7, N. 1 - pág. 333-355 janeiroabril de 2021: "Pedagogias Vitais: Corpo, Desejo e Educação" DOI: 10.12957/ riae.2021.54793 
prática política, clínica e pedagógica. Ao assumirmos papéis de testemunha externa e movedor, o movimento autêntico revelou-se uma ferramenta interessante na busca pela singularidade na vida em comunidade. A testemunha, que observa atentamente os movimentos de outro corpo, ao dar o retorno sobre esse movimento, o faz localizando-o em seu próprio corpo, por meio dos verbos de significações e relações com o mundo distintas - ver, pensar e sentir - conjugados em primeira pessoa. Aprender a distinguir o que viu do que sentiu com o movimento do outro nos ajudava a nos situar em nossos julgamentos.

$\mathrm{Na}$ crítica aos essencialismos científicos, deixar-se afetar era um dispositivo metodológico importante. De acordo com Jeanne Favret-Saada (2005), não se trata de se imaginar no lugar do outro, nem supõe uma identificação. Portanto, deixar-se afetar se distancia da ideia de empatia, nem informa sobre o outro, mas "mobiliza e modifica o próprio estoque de imagens" (FAVRET-SAADA, 2005, p 159), abrindo a comunicação desprovida de intencionalidade, que pode ser verbal ou não verbal. Quando é verbal não é a descrição do vivido, mas diz respeito ao que a experiência estimulou, uma cartografia do que nos moveu. A comunicação não verbal está baseada na comunicação das intensidades. Trata-se, sobretudo, de uma percepção não significada, presente no corpo, própria dos processos de desterritorialização que precedem a criação de novas formas.

Os afetos não surgem da individualidade dos corpos. "A própria palavra afetar designa o efeito da ação de um corpo sobre outro, em seu encontro" (ROLNIK, 2007, p 37), de modo que era no encontro dos corpos (com outros corpos ou o que o rodeia) que novos universos psicossociais eram produzidos. Em um movimento contínuo de desencantamento dos afetos, repertórios cristalizados se tornam obsoletos (ROLNIK, 2007). É assim que o desejo, compreendido aqui como força criadora de existência, flui. A aposta aqui é que os afetos promovidos pelos encontros possam fluir para a criação de novos sentidos, sair do repertório conhecido que não abre caminhos para conexões mais afinadas ao presente.

A impossibilidade da conexão entre os afetos é o que, segundo Suely Rolnik (2007), caotiza a existência. No movimento da vida, que é uma constante produção de encontros e afetos, estes precisam passar e ressignificar as relações. Em um dos jovens, a orientação homossexual e o sentimento de que sua estética masculina era inadequada, desorganizava seus sentimentos e reações. Aos poucos, seus afetos ganhavam passagem no movimento com o grupo. Conforme eram acolhidos pelo coletivo, ganhavam significados distintos. Ele (hoje ela) passou a criar projetos sociais e construiu espaços de luta e de criação de existência.

A constelação dos afetos resultante do contato com o outro, humano ou não humano, é capaz de formar uma realidade corpórea que, embora invisível, não é menos real. No encontro Revista Interinstitucional Artes de Educar. Rio de Janeiro, V. 7, N. 1 - pág. 333-355 janeiroabril de 2021: "Pedagogias Vitais: Corpo, Desejo e Educação" DOI: 10.12957/riae.2021.54793 


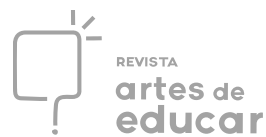

com os grupos, parecia ser justamente a produção do que Suely Rolnik (2007) chama de um corpo vibrátil o que gerava agenciamentos que faziam sentido. Assim, segundo as análises do trabalho de Lygia Clark realizadas por Suely Rolnik (1999), é a partir da escuta do corpo vibrátil que somos compelidos a criar novas paisagens existenciais. Desse modo, o enfrentamento das universalizações subjetivantes - que não acolhem a vida em sua diversidade - passa por criar um corpo sensível ao efeito dos encontros, um corpo que pulsa, que vibra, mergulhado nas intensidades - energia que surge dos agenciamentos que fazem os corpos em sua qualidade de vibráteis.

Tais configurações requerem, assim, considerar o corpo em seu potencial expressivo, em sua vibração, não um corpo orgânico, mas "um corpo sem órgãos" (DELEUZE e GUATTARI, 1996, p. 9). O corpo aqui não é definido como uma unidade psicofísica, com base nas contribuições de José Gil (2004). O corpo é sim, dotado de intencionalidade e consciência do corpo, que seria, de acordo com Gil (2004), o avesso da intencionalidade. Ser o avesso da intencionalidade significa que a consciência do corpo não é subliminar, nem é a consciência que se tem do corpo, seus órgãos e membros, mas é a impregnação da consciência pelo corpo; a captação das mais finas vibrações e intensidades do mundo pelo corpo, sem que estas intensidades ganhem definição clara pela consciência.

Helia Borges $\left(2009^{a}\right)$, explica que "estamos tão impregnados de um modo de ver o mundo que não nos damos conta das micropercepções que atravessam nosso corpo no cotidiano revelando-nos o abismo de possibilidades característico da vida em sua existência" (p. 36). Abrir o corpo é, portanto, deixar vir à tona a consciência do corpo, espaço privilegiado de agenciamentos. É criar a zona em que o corpo se deixa ser contagiado pelo mundo, por meio de micropercepções. Em outras palavras, abrir o corpo é abrir o espaço de agenciamento de fluxos de intensidades, para que fluam por vias diversas (GIL, 2004).

Tornar um corpo vibrátil, desse modo, significa abri-lo, deixar-se afetar, colocar em evidência as micropercepções e possibilitar a criação de modos de existência não tão rigidamente baseados em normas pré-estabelecidas, como as normas de gênero. Devemos aproveitar e ampliar o campo de afetação deste corpo, produzindo movimentos e o contato com uma série de objetos e outros corpos que aumentam a sensibilidade da consciência do corpo, esquecida por nossa escolarização via reprodução de moralismos e raciocínio esvaziado da experiência. São experiências, toques, produzir sentidos por meio do sentir, que ampliam nosso universo de afetação.

Por meio da arte, buscávamos encontrar formas não ensaiadas de contato com o mundo, que nos conduzem a novos horizontes perceptivos, repertórios não muito conhecidos. Na sala Revista Interinstitucional Artes de Educar. Rio de Janeiro, V. 7, N. 1 - pág. 333-355 janeiroabril de 2021: "Pedagogias Vitais: Corpo, Desejo e Educação" DOI: 10.12957/riae.2021.54793 
que nos foi disponibilizada, produzimos, em colaboração com a professora de arte, objetos que nos remeteram a obra de Lygia Clark. Retomando a obra e a história dessa artista, Rolnik (1999) analisa como ela, por meio de sua arte, cria pouco a pouco as condições para estimular a criação de um corpo vibrátil. Lygia Clark buscava descobrir o que há de mais profundo no corpo, a partir de experimentos que reativam o campo de afetação corporal.

Na obra de Lygia Clark, o público é convidado a manipular os objetos criados pela artista, de modo que tais objetos se revelam relacionais - e não mais neutros e indiferentes, para uma subjetividade não mais estruturada por uma identidade fixa e anestesiada para os movimentos da vida. Não é a possibilidade de transferência com a obra que é explorada, mas a potência criativa do espectador, ao abrir-se para a relação com o objeto. Assim, o que passa a interessar é não o objeto em si, mas de que modo a relação entre os corpos (humano e objeto de arte) podem produzir transformações nesta subjetividade (FONSECA, 2011). Segundo Rolnik (1999), o acento na proposta de Lygia não está na recomposição de uma identidade, nem possui fins terapêuticos. Mas explorando o potencial terapêutico da arte, são criadas condições de escuta do corpo vibrátil, em que a experiência de um vazio-pleno opera " $a$ silenciosa incubação de uma nova realidade sensível" (Rolnik, 1999), essencial para a manifestação da potência de diferenciação da vida. A experiência de vazio-pleno corresponde ao momento em que o corpo vibrátil está operando. De um vazio vivido como tal, atravessado por sentimentos de perda, de falta de equilíbrio, surge um "vazio pleno, cheio de nova significação” (Rolnik, 1999, p. 321).

Nos grupos, eram os afetos surgidos nos encontros entre os corpos (entre humanos e entre humanos e obras de arte) eram tomados como objeto de investigação frequente, tal como mencionado. A distinção entre o visto e o sentido, nos ajudava a rastrear nossos posicionamentos e a fazer uma cartografia de nós mesmos, de nossas sensações, que não tinha como objetivo buscar uma essência, mas se ouvir e construir novas possibilidades de existir. Dito isso, vale dizer que os experimentos aqui narrados utilizavam propostas muito simples e respeitosas à disponibilidade de cada um/ uma de se mover e se relacionar com o entorno. $\mathrm{O}$ mais importante era produzir relações outras que desencadeassem o pensar, que rompessem repertórios conhecidos, conectando-nos à vida, aos afetos, para a construção de bordas que deixassem fluir nossas potências criativas de existência. Nesse sentido, era propor modos de fazer emergir analisadores ${ }^{\mathrm{x}}$. Outras tarefas, outras relações, outra atenção para a experiência e para o corpo ajudavam a romper com a prática da reprodução dos conteúdos aprendidos, em que dinâmicas de grupos também não estão livres quando apenas usam estratégias para que os grupos assimilem de modo mais fácil o que se quer transmitir. 


\section{Amarrando alguns nós dessa trama: a transformação como processo}

As transformações não se restringiram ao curto espaço de tempo das intervenções. Anos depois, viraram lideranças, profissionais na área do gênero ou são acadêmicos/as. Incorporaram o tema de muitas maneiras em suas práticas. Seguem muitos caminhos para romper com as normas de gênero: a dança, a educação, o movimento social, o acolhimento de pares, a política institucional, entre outros. Suas ações de gênero são articuladas com outras marcas: raça ou transgeneridade, por exemplo. Assim como eu, seus modos de ser e de perceber as normas de gênero não cessam de se transformar, conforme aprendem com suas experiências e entram em contato com novos pensamentos. Os modelos de homem ou de mulher transformados ou desconstruídos, dos exercícios de grupo, não fazem sentido, uma vez que percebemos que é um corpo aberto à transformação, a uma relação outra com a experiência e com os afetos que atravessam os corpos que parece subverter o sistema que captura nossas possibilidades criativas de existência e de criação de mundos que respeitem a singularidade. Falávamos de pessoas em transformação.

Não havia modelos alternativos/ transformadores de masculinidades ou feminilidades que coubessem as jovens que estavam dando passagem a transgeneridade. Romper com a naturalização das masculinidades não se restringia a oferecer outras narrativas para a mesma identidade. Era necessário deixar aparecer e acolher as expressões que não deixavam de ser criadas e que não cabiam nos moldes masculinos e femininos, nem estavam prontas para serem nomeadas por nenhum dos rótulos conhecidos. Com os jovens negros, os modelos de homens não violentos eram insuficientes para dar conta da análise do corpo negro como ameaça nas ruas.

É importante mencionar que não se trata aqui de negar a relevância olhar para os lugares ocupados pelas mulheres e pelos homens e suas consequiências substanciais, ou de dispensar a luta política organizada por sujeitos cujos marcadores sociais produzem efeitos concretos. No entanto, no encontro com os grupos, era necessário trazer à tona a complexidade de afetos que atravessavam os corpos e revelavam as contradições e a porosidade das fronteiras do gênero. Era preciso observar o que escapava e sua relação com as formas vividas. Como apontam as análises feministas apresentadas aqui, se por um lado somos incitados frequentemente a nos comportar e a desejar de determinada maneira, a partir de nossas marcas corporais, por outro lado, no movimento da vida, novos desejos e modos de existência são produzidos. Necessitamos acolhe-los. Desse modo, consideramos que atribuir lugar de relevância ao corpo nas intervenções para emancipação de gênero não se resume a discutir a relação entre corpo e Revista Interinstitucional Artes de Educar. Rio de Janeiro, V. 7, N. 1 - pág. 333-355 janeiroabril de 2021: "Pedagogias Vitais: Corpo, Desejo e Educação" DOI: 10.12957/riae.2021.54793 


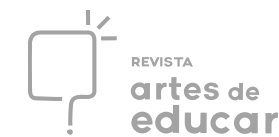

as normas de gênero, mas desincorporar performances avidamente enraizadas nos corpos, dar forma a novas possibilidades de existência.

O trabalho com os grupos revelou que a transformação de gênero é efeito da potencialização de um movimento que produz rupturas nos rituais cotidianos, naturalizados, e os transforma em analisadores necessários a constituição de campos problemáticos da existência (ROCHA, 2007). Além de transformação ser um processo, não um fim, não pode ter um modelo a ser alcançado. Trata-se de abrir para a criação de modos singulares de existência, o que não se alcança simplesmente pela reprodução de conhecimentos e comportamentos.

O trabalho de transformação das normas de gênero, visando à luta contra as opressões, requer desafiar a privação do acesso criativo a variedade dos afetos que nos atravessam pelos regimes cisheteropatriarcais-coloniais-capitalísticos, e que nos incita a copiar modelos de como nos comportar e produzir conhecimento. $\mathrm{O}$ que as intervenções sobre gênero com jovens têm destacado é que não apenas um aliado da sociedade colonial-capitalística em seu mecanismo de controle, o corpo também se articula à capacidade inventiva dos sujeitos (BORGES, 2009). A partir das conexões possibilitadas pelos encontros, somos permeados por fontes que engendram novas possibilidades aos sentidos atribuídos as coisas do mundo.

Cabe mencionar que não é qualquer modo de trazer o corpo para a cena que é dispositivo que mobiliza deslocamentos. É a atenção que o trabalho pode oferecer às relações, às ressonâncias e aos nossos lugares de poder. Desse modo, intervenções para transformações de gênero precisam vir acompanhadas de um processo integrado de profundas mudanças na concepção/ relação das instituições de educação. Dançar de diferentes formas, dançar o gênero, observar o que nos acontece, ensaiar devolver para as outras e outros o que observamos dos seus e dos nossos movimentos, foi uma forma que encontrei para trazer o corpo para a cena do grupo. Mas nem a dança é ferramenta capaz de, por si só, reverberar singularidades, como não é a única possibilidade de produzir abertura nos corpos. Cada ferramenta sacada demanda atenção para o vivido, para nossas potências e incômodos gerados pelas relações dos corpos com os coletivos.

\section{REFERÊNCIAS}

AGUIAR, Katia. \& ROCHA, Marisa. Micropolítica e o Exercício da Pesquisa-intervenção: Referenciais e Dispositivos em Análise. Psicologia: ciência e profissão. Brasília, n. 4, v. 27 , p. 648-663, dez 2007. 
AGUIAR, Katia. Práticas de formação e a produção de políticas de existência. Psicologia \& Sociedade, [S.I.], v. 24 (n.spe), p. 60-66, 2012.

ARÁN, M. e PEIXOTO Jr., C.A.Vulnerabilidade e vida nua: bioética e política na atualidade. Revista de Saúde Pública. Rio de Janeiro: Instituto de Medicina Social, 2007.

BORGES, Hélia. Sobre o movimento: o corpo e a clínica. Tese. Doutorado. Programa de Pósgraduação em Saúde Coletiva, do Instituto de Medicina Social da Universidade do Estado do Rio de Janeiro. Rio de Janeiro, 2009.

BUTLER, Judith. Problemas de Gênero: Feminismo e subversão da identidade. Rio de Janeiro: Civilização Brasileira, 2008.

Regulações de Gênero. Cadernos pagu, v. 42, p. 249-274, jan/jun. 2014.

CONNEL, Raewyn. Gênero em termos reais. São Paulo: nVersos, 2016.

CRENSHAW, Kimberle. Documento para o encontro de especialistas em aspectos da discriminação racial relativos ao gênero. Estudos Feministas, v. 10, n.1, p. 171-188, 2002.

DELEUZE, Gilles; GUATTARI, Félix. Mil Platôs: capitalismo e esquizofrenia, vol. 3. São Paulo: Editora 34, 1996.

DONINI, Angela A. Desurdir a lógica do gênero. 2010. Tese (Doutorado em Psicologia) Pontifícia Universidade Católica de São Paulo, São Paulo, 2010, 130 f.

FAVRET-SAADA, Jeanne. Ser afetado. Cadernos de Campo, n.13, pp 155-161, 2005.

FONSECA, Vanessa do N. Corpo, Direitos e Educação: Promovendo equidade de gênero através do movimento na escola.Pós-graduação lato sensu (Terapia através do Movimento. Corpo e Subjetivação). Faculdade Escola Angel Vianna, Rio de Janeiro, 56 p., 2011.

"Precisamos falar com os homens?": uma análise das intervenções nas masculinidades do Norte para o Sul. Tese (Doutorado em Psicologia) - Instituto de Psicologia, Universidade Federal Fluminense. Niterói -RJ, p. 264, 2019.

FOUCAULT, Michel. Ditos e escritos IX: genealogia da ética, subjetividade e sexualidade. Rio de Janeiro: Forense Universitária, 2014.

FUGANTI, Luiz. Saúde, desejo e pensamento. São Paulo: Aderaldo \& Rothschild Ed.: Linha de Fuga, 2008.

GIL, José. Abrir o corpo. In: FONSECA, T. M. G. e ENGELMAN, S. Porto Alegre: Editora da UFRGS, 2004.

GUTIÈRREZ AGUILAR, Raquel. La lucha de lasmujeres contra todas lasviolências em México: reunir fragmentos para hallar sentido. Em: GAGO, Veronica et al. $8 M$ Constelatión feminista.Ciudad Autónoma de Buenos Aires: Tinta Limón, 2018. 
HARAWAY, Donna. Saberes localizados: a questão da ciência para o feminismo e o o privilégio da perspectiva parcial. Cadernos Pagu, 1995, v. 5, p 07- 41

LAURETIS, Teresa de. A tecnologia de gênero. Em: HOLLANDA, Heloisa Burarquede (org). Pensamento feminista/ conceitos fundamentais. Rio de Janeiro: Bazar do Tempo, 2019.

LORDE, Audre. Idade, raça, classe e gênero: mulheres redefinindo a diferença. Em: HOLLANDA, Heloisa Burarque de (org). Pensamento feminista/ conceitos fundamentais. Rio de Janeiro: Bazar do Tempo, 2019.

LATOUR, Bruno. Jamais fomos modernos: ensaio de antropologia simétrica. São Paulo: Editora 34, 2013.

McLAREN, Margaret. Foucault, Feminismo e Subjetividade. São Paulo: Intermeios, 2016.

NICHOLSON, Linda. “Interpretando o gênero”. Revista Estudos Feministas. v.8, n.2, 2000.

OYĚWÙMÍ, Oyèrónké. Conceptualizing Gender: The Eurocentric Foundations of Feminist Concepts and the challenge of African Epistemologies. African Gender Scholarship: Concepts, Methodologies and Paradigms. CODESRIA Gender Series. Volume 1, Dakar, CODESRIA, 2004, p. 1-8 por Tradução para uso didático de Juliana Araújo Lopes.

PAREDES, Julieta. Hilando fino. Desde el feminismo comunitário. La Paz: Creative Commons, 2010.

PAULON, Simoni Mainieri e ROMAGNOLI, Roberta Carvalho. Pesquisa-intervenção e cartografia: melindres e meandros metodológicos. Estudos e Pesquisas em Psicologia. Rio de janeiro: UERJ, ano 10, n. 1, p. 85-102, 2010.

ROLNIK, Sueli. Molda-se uma alma contemporânea: o vazio pleno de Lygia Clark. Em: The Experimental Exercise of Freedom: Lygia Clark, Gego, Mathias Goeritz, Hélio Oiticica and Mira Schendel. Los Angeles: The Museum of Contemporary Art, 1999. Disponível em: Acesso em: 02 de julho de 2019.

Cartografia Sentimental: Transformações Contemporâneas do Desejo. Porto Alegre: Sulina; Editora da UFRGS, 2007.

Esferas da Insurreição: notas para uma vida não cafetinada. São Paulo: N-1 Edições, 2018.SILVA, 2005.

SOUZA, N.G.S. , ARNT A. e RABUSKE, A. A fabricação do corpo: efeitos da disciplinarização dos saberes e do corpo nas práticas escolares.Gênero: Revista do Núcleo Transdisciplinar de Estudos de Gênero - NUTEG 7(2): 115-134. Niterói: EdUFF 2007.

SALIH, Sara. Judith Butler e a Teoria Queer. Belo Horizonte: Autêntica Editora, 2012.

VICTORA, C. G., KNAUTH, D. R. e RASSEN, M. N. A. Pesquisa Qualitativa em Saúde: uma Introdução ao Tema. Porto Alegre: Tomo Editorial, 2000. 
WEEKS, J. O Corpo e a Sexualidade. In: LOURO, G. L (org). O corpo educado: Pedagogias da Sexualidade. Belo Horizonte: Autêntica, 2000.

\begin{abstract}
${ }^{\text {i }}$ Embora não seja especificamente o tema da tese, esse artigo traz reflexões que fizeram parte do trabalho de conclusão de doutoramento da autora, que analisou estratégias de envolvimento dos homens na transformação das masculinidades, a partir de uma perspectiva decolonial e interseccional. As experiências aqui narradas, bem como alguns trechos foram retirados desse trabalho. Para a referência dea tese, ver Fonseca (2019).

ii Doutora em Psicologia pela Universidade Federal Fluminense. Mestre em Psicossociologia de comunidades pelo Programa Interdisciplinar de Comunidades e Ecologia Social - EICOS (2004). Formada em psicologia pela Universidade Federal do Rio de Janeiro. Seus temas de trabalho e pesquisa são: gênero, masculinidades, engajamento dos homens na equidade de gênero, paternidade, direitos sexuais e direitos reprodutivos, violências de gênero e contra crianças, exploração sexual de crianças e adolescentes, prevenção das DST e HIV, produção de metodologias transformativas de gênero, psicologia social comunitária. É consultora internacional para pesquisas e programas de envolvimento masculino na promoção da equidade de gênero e saúde, tendo realizado consultorias para agências internacionais, governos e organizações não governamentais de Moçambique, Mali, Costa do Marfim, Paraguai, Peru e Honduras, além da adaptação de materiais educativos e palestras sobre o tema em outros países. É pesquisadora-colaboradora do Núcleo de Pesquisa e Desconstrução de Gênero - DEGENERA/ UERJ. ORCID https://orcid.org/0000-0003-4423-3298
\end{abstract}

iiié uma escala psicométrica, aplicada em formato de questionário, em que o entrevistado é convidado a responder sobre seu grau de concordância com determinada afirmação. Por exemplo, "existem momentos em que uma mulher merece apanhar" ou "a equipe de vendas presta excelente trabalho". Dentre as opções de resposta estão:1)discordo totalmente, 2) discordo, 3) indiferente (ou neutro), 4) concordo e 5) concordo totalmente. Foi desenvolvida nos Estados Unidos na década de 30, por RensisLikert.

${ }^{\text {iv }}$ Os exercícios de grupo mencionados podem ser encontrados nos currículos disponíveis nos seguintes links: https://promundo.org.br/recursos/manual-m/; $\quad$ https://promundo.org.br/recursos/manual-h-trabalhando-comhomens-jovens/.

${ }^{\mathrm{v}}$ Compreendendo que o marketing se valeu mais da "venda" de estilos de vida do que divulgou os atributos de seus produtos para disseminá-los, uma das formas de buscar influenciar os comportamentos masculinos se baseia na concepção de marketing social, em que estilos de vida alternativos aos hegemônicos são divulgados no intuito de produzir resultados positivos nos cuidados com a saúde e na prevenção de violências de gênero.

${ }^{\mathrm{vi}} \mathrm{A}$ partir de referências do conceito desenvolvido por Gilles Deleuze e Félix Guatarri, pesquisadores de Institutos de Psicologia no Brasil, sobretudo da Universidade Federal Fluminense, Universidade Federal do Rio de Janeiro e da PUC de São Paulo, têm desenvolvido a cartografia como método de acompanhamento da dinâmica e dos deslocamentos dos processos interventivos (Passos, Kastrup e Escóssia, 2009).

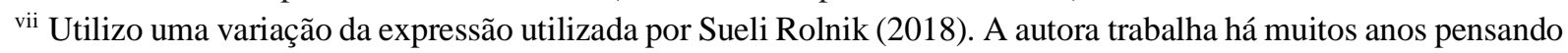
as interrupções capitalísticas dos "processos de singularização que se desencadeariam nos encontros entre os corpos e seus idiomas próprios" (ROLNIK, 2018, p. 103), a partir das propostas de Félix Guattari, com quem estabeleceu parcerias de trabalho. O sufixo "ístico" foi acrescentado por Guattari à palavra capitalista para denotar a sobrecodificação deste regime, que incide sobre todos os domínios da existência humana, conforme salienta a autora.

viii $\mathrm{O}$ termo heterossexualidade compulsória foi utilizado por Butler em Problemas de Gênero, para tratar do regime das normas de gênero. Cisheterossexualidade é a junção de cisgeneridade e heterossexualidade. É expressão bastante usada pelo movimento de transgêneros e travestis. A palavra cisgêneridade indica a conformidade de expressão com o gênero designado no nascimento. $O$ termo ganhou uso a partir de críticas ao uso da palavra "normal" para a indicação de pessoas não transgêneras. 
ix Angel Vianna é bailarina, coreógrafa, professora e pesquisadora. Fundou faculdade escola de dança que leva seu nome. Suas pesquisas se voltam para a conscientização do movimento e sensibilização do corpo. Seus métodos são aplicados não apenas na dança, mas na clínica também.

${ }^{x}$ De acordo com a pesquisa-intervenção. Trata-se do que se apresenta para ser analisado. 